\title{
Short communication: The effects of offering a high or low plane of milk preweaning on insulin-like growth factor and insulin- like growth factor binding proteins in dairy heifer calves
}

\author{
J. Haisan, ${ }^{*}$ M. Oba, ${ }^{*}$ D. J. Ambrose,${ }^{*} \dagger$ and M. A. Steele ${ }^{* 1}$ \\ *Department of Agricultural, Food and Nutritional Science, University of Alberta, Edmonton, T6G 2P5, Canada \\ †Livestock Research Section, Alberta Agriculture and Forestry, Edmonton, T6H 5T6, Canada
}

\begin{abstract}
Although positive effects on growth have been shown when calves are placed on high planes of nutrition, little information exists regarding the effect of this feeding strategy on insulin-like growth factor-1 (IGF-1), a hormone whose fundamental action is to stimulate growth, and its binding proteins during the preweaning period. The objective of this study was to characterize IGF-1 and insulin-like growth factor binding protein (IGFBP) concentrations in plasma during the pre- and immediate postweaning period, when calves were offered a high or low plane of whole milk. Twenty-six female Holstein calves were randomly assigned to either a high (HI; 10 $\mathrm{L} / \mathrm{d} ; \mathrm{n}=13)$ or low $(\mathrm{LO} ; 5 \mathrm{~L} / \mathrm{d} ; \mathrm{n}=13)$ plane of milk following colostrum feeding at $\mathrm{d} 3$ of life. Calves were fed their respective diet as whole milk until d 48 when a $10-\mathrm{d}$ weaning transition began. During this transition, milk was reduced by $10 \%$ per day such that all calves received no milk on d 59 of life. Blood samples were collected bi-weekly to measure IGF-1 and IGFBP in plasma. Calves fed HI gained more body weight than calves fed LO during the preweaning period (d 1-48 of life; 0.90 vs. $0.65 \mathrm{~kg} / \mathrm{d}$ ); however, no differences in average daily gain or metabolizable energy intake during the weaning transition (d 48-58 of life) or postweaning period (d 59-70 of life) occurred. Concentrations of IGF-1 were higher in HI calves during the preweaning period, which was associated with high levels of IGFBP-3 at wk 5 and lower IGFBP-2 during each measured time point preweaning as compared with LO. Insulin-like growth factor binding protein-4 was lower in HI calves only during wk 1, and IGFBP-5 was not affected by the dietary treatment. Overall, offering a high plane of nutrition was associated with changes in plasma IGF-1 and IGFBP that would indicate greater
\end{abstract}

Received December 22, 2017.

Accepted July 22, 2018.

${ }^{1}$ Corresponding author: masteele@ualberta.ca growth and development preweaning but not necessarily postweaning.

Key words: weaning, dairy calf, metabolizable energy intake

\section{Short Communication}

Extensive research has been conducted in the neonatal ruminant regarding the effect of early postnatal nutrition on gut development, metabolism, and immunity, with the primary focus being colostrum. Within this, it has been shown that colostrum feeding acts to mature the somatotropic axis (Hammon et al., 2012), an axis consisting primarily of growth hormone, IGF-1 and IGF-2, and their associated carrier proteins and receptors (Renaville et al., 2002). The somatotropic axis is the primary regulator of postnatal growth and development in cattle (Hammon and Blum, 1997; Hammon et al., 2000), making it an area of interest where growth regulation is concerned. However, action of IGF-1 is primarily regulated by 6 IGF binding proteins (IGFBP-1 through IGFBP-6; Yu et al., 1999), each acting on specific cells or tissues with inhibitory or stimulatory effects, making their role an area of interest.

Recently it has been shown that increased nutrient intake from milk replacer stimulates IGF-1 secretion and increases IGF-1 blood concentration in calves (Bartlett et al., 2006; Daniels et al., 2008; Schaff et al., 2016). However, it is unknown what effects a high plane of nutrition attained by feeding whole milk, instead of milk replacer, as in prior studies preweaning has on plasma concentrations of IGF-1 and IGFBP concentrations, and whether the effects, if any, last throughout the entire preweaning and immediate postweaning periods.

The objective of this study was to determine the effects of providing a high plane of nutrition (by feeding a greater amount of whole milk) on plasma concentrations of IGF-1 and IGFBP in dairy heifer calves. We hypothesized that a high plane of milk would increase the concentrations of plasma IGF-1 and modulate the concentration of IGFBP. 
All procedures were preapproved by the Animal Care and Use Committee for Livestock at the University of Alberta (AUP 1553). To remove any bias from colostrum feeding, calves were each fed one meal of reconstituted powdered colostrum (HeadStart, Saskatoon Colostrum Company Ltd., Saskatoon, SK, Canada) delivering 120 $\mathrm{g}$ of $\operatorname{IgG}$ within $6 \mathrm{~h}$ of life followed by 3 meals of pooled, pasteurized colostrum $(2 \mathrm{~L}$ each, approximately $12 \mathrm{~h}$ apart) during the first $2 \mathrm{~d}$ after birth before being balanced for birth BW and randomly assigned to either a high $(\mathbf{H I} ; 10 \mathrm{~L} / \mathrm{d} ; \mathrm{n}=13)$ or low $(\mathbf{L O} ; 5 \mathrm{~L} / \mathrm{d} ; \mathrm{n}=$ 13) level of whole milk. All calves were allowed $2.5 \mathrm{~L}$ of pasteurized (heated to $60^{\circ} \mathrm{C}$ for $60 \mathrm{~min}$ ) whole milk per feeding. Milk samples were taken daily and analyzed for concentrations of milk fat, $\mathrm{CP}$, and lactose at the Alberta Central Milk Testing Laboratory (Edmonton, Alberta, Canada; AOAC International, 2002), and ME was calculated to be $5.16 \mathrm{Mcal} / \mathrm{kg}$ of DM according to NRC (2001). Calves were offered their respective milk treatment for $49 \mathrm{~d}$ before a 10-d weaning transition where milk was reduced by $10 \%$ per day, resulting in all calves weaned at d 59. Calves were offered milk, but not forced to consume their offered amounts, in an attempt to simulate a commercial feeding scenario. Calves were housed in individual pens and offered milk using the Calf Rail (Foerster-Technik, Engen, Germany) feeding system for the first $19 \pm 3 \mathrm{~d}$ before being moved to a group pen and fed through an automated calf feeder (CF1000+, DeLaval Canada, ON, Canada). Calf feeding times were $0600,1100,1600$, and $2200 \mathrm{~h}(4 \times / \mathrm{d})$ for $\mathrm{HI}$, and at 1100 and $2200 \mathrm{~h}(2 \times / \mathrm{d})$ for LO. The amount of milk dispensed to each calf was measured automatically through the feeding systems and recorded to provide daily intake on an individual animal basis. The system is calibrated based on weight and revolutions of a feeding pump for accurate intakes such that if a calf leaves the feeding stall with unconsumed milk remaining, only what was dispensed to the nipple is recorded. Water and starter ration (Advantage 4 Dairy Calf Starter Plus, HiPro Feeds, Olds, AB, Canada; $20 \%$ CP, 35\% starch, and $2.71 \mathrm{Mcal} / \mathrm{kg}$ of $\mathrm{ME}$; as reported by the manufacturer) were provided ad libitum from 3 to $70 \mathrm{~d}$ of life. Starter intake was not measured during the first $19 \pm 3$ d of life due to pen design and contamination of starter by water as pails used to feed starter were adjacent to water pails. Starter intake was recorded automatically from $19 \pm 3$ to $70 \mathrm{~d}$ using BioControl bunks (BioControl, Rakkestad, Norway). BioControl bunks identify calves through a radio-frequency identification tag, and record the feed disappearance from the bunk when calves are eating. Calves were offered chopped alfalfa hay ad libitum from $19 \pm 3$ to $70 \mathrm{~d}$ in a separate BioControl bunk; however, intake data were not recorded due to inaccuracies in measuring the small quantities consumed.

Calves were assigned to 1 of 2 sampling days: Monday or Thursday based on the day they were born; sampling occurred between 0830 and $0930 \mathrm{~h}$ on these days. Body weights were measured weekly and a $10-\mathrm{mL}$ blood sample was obtained every 2 wk from the jugular vein into tubes containing sodium heparin (BD Vacutainer, Franklin Lakes, NJ). Following collection, blood samples were immediately placed on ice and treated with $5 \mu \mathrm{L}$ of aprotinin $(0.01 \mathrm{mg} / \mu \mathrm{L}$; CAS: $9087-70-1$, Sigma, St. Louis, MO) before centrifugation at 3,000 $\times$ $g$ for 20 min at $4^{\circ} \mathrm{C}$ and stored at $-20^{\circ} \mathrm{C}$ until analysis. Plasma samples were analyzed for IGF-1 at Prairie Diagnostic Services (University of Saskatchewan, Saskatoon, SK, Canada) using a solid-phase, enzymelabeled, chemiluminescent immunometric assay using a commercially available kit (Immulite 1000 analyzer, Siemens, Oakville, ON, Canada), and IGFBP-2, -3, -4, and -5 using quantitative Western Ligand Blot at a commercial laboratory (Ligandis Biomarker Diagnostics, Gustrow, Germany).

Data were analyzed separately for each week using the FIT model of JMP (version 13.1.0; SAS Institute, Cary, NC) according to the following model:

$$
\mathrm{Y}_{\mathrm{ij}}=\mu+\mathrm{T}_{\mathrm{i}}+\mathrm{C}_{\mathrm{j}}+\mathrm{e}_{\mathrm{ij}},
$$

where $Y_{i j}$ is the dependent variable, $\mu$ is the overall mean, $T_{i}$ is the fixed effect of treatment, $C_{j}$ is the random effect of calf, and $\mathrm{e}_{\mathrm{ij}}$ is the residual error. Correlations were analyzed using the MULTIVARIATE method of JMP.

Retrospective radial immunodiffusion analysis as described by Chelack et al. (1993) and Chamorro et al. (2014) showed no difference in serum proteins (5.3 vs. $5.1 \pm 0.30 \mathrm{~g} / \mathrm{L}, P=0.59)$ or immunoglobulins (15.4 vs. $15.8 \pm 1.36 \mathrm{~g} / \mathrm{L} ; P=0.37)$ for $\mathrm{HI}$ vs. $\mathrm{LO}$ calves, respectively, at $4 \pm 3 \mathrm{~d}$ of life, and no difference in incidence of disease was observed. By design, milk intake of HI calves was greater than that of LO within the first week of life $(7.86$ vs. $4.66 \pm 0.26 \mathrm{~L} / \mathrm{d} ; P<0.01)$ and remained consistently greater until d 48 when weaning began ( 8.86 vs. $4.68 \pm 0.48 \mathrm{~L} / \mathrm{d} ; P<0.01$; Figure $1 \mathrm{~A}$ ). Milk intake was less than targeted, which is attributed to feeder settings. The software within the calf feeder calculates the amount of milk calves accumulate each hour based on a 24-h day, until they reach the amount set for each meal (e.g., $12 \mathrm{~L} / \mathrm{d}$ target intake = calves accumulate $0.5 \mathrm{~L} / \mathrm{h}$ ), and once enough milk has been accumulated to meet the minimum meal size calves will be fed. However, when calves were housed in the individual pens and fed with the calf rail, feeding times 
were preset and calves only had the opportunity to consume milk at these times. If a calf did not get up to drink when the rail was in front of its pen, the feeding was missed. Similarly, when calves were in the group pen, the same feeder settings were applied; however, feeding was restricted such that it did not begin until $0600 \mathrm{~h}$ as in the individual pens. The tight restriction on meal size $(2.5 \mathrm{~L} /$ meal) limited when calves could drink, and timing of visits to the feeder would dictate their intake.

Automated calf feeders have been used in research and industry to feed large amount of milk to calves successfully; however, in both scenarios minimal information has been published regarding the settings mentioned above. Meal size is a large contributor to how much milk the calves receive per day and is typi- cally set with a large range. For example, Rosenberger et al. (2017) set the minimum per visit at $0.5 \mathrm{~L}$, with no maximum, which would in theory allow a calf consuming $10 \mathrm{~L} / \mathrm{d}$ to visit the feeder up to 20 times. In addition, with no maximum per visit, the calf has more flexibility as to when it receives milk. Similarly, Schaff et al. (2016) indicated that calves were allowed to consume $2 \mathrm{~L}$ per visit with no explanation of what the minimum amount was. Because of this, it is plausible that calves were visiting the calf feeder when they had accumulated from 0.5 to $2.0 \mathrm{~L}$, which is less restrictive on when calves consume and how much they get per day. In comparison, with our feeder settings calves could be fed only 4 times per day, meaning calves had little opportunity to make up milk intake from a missed feeding.
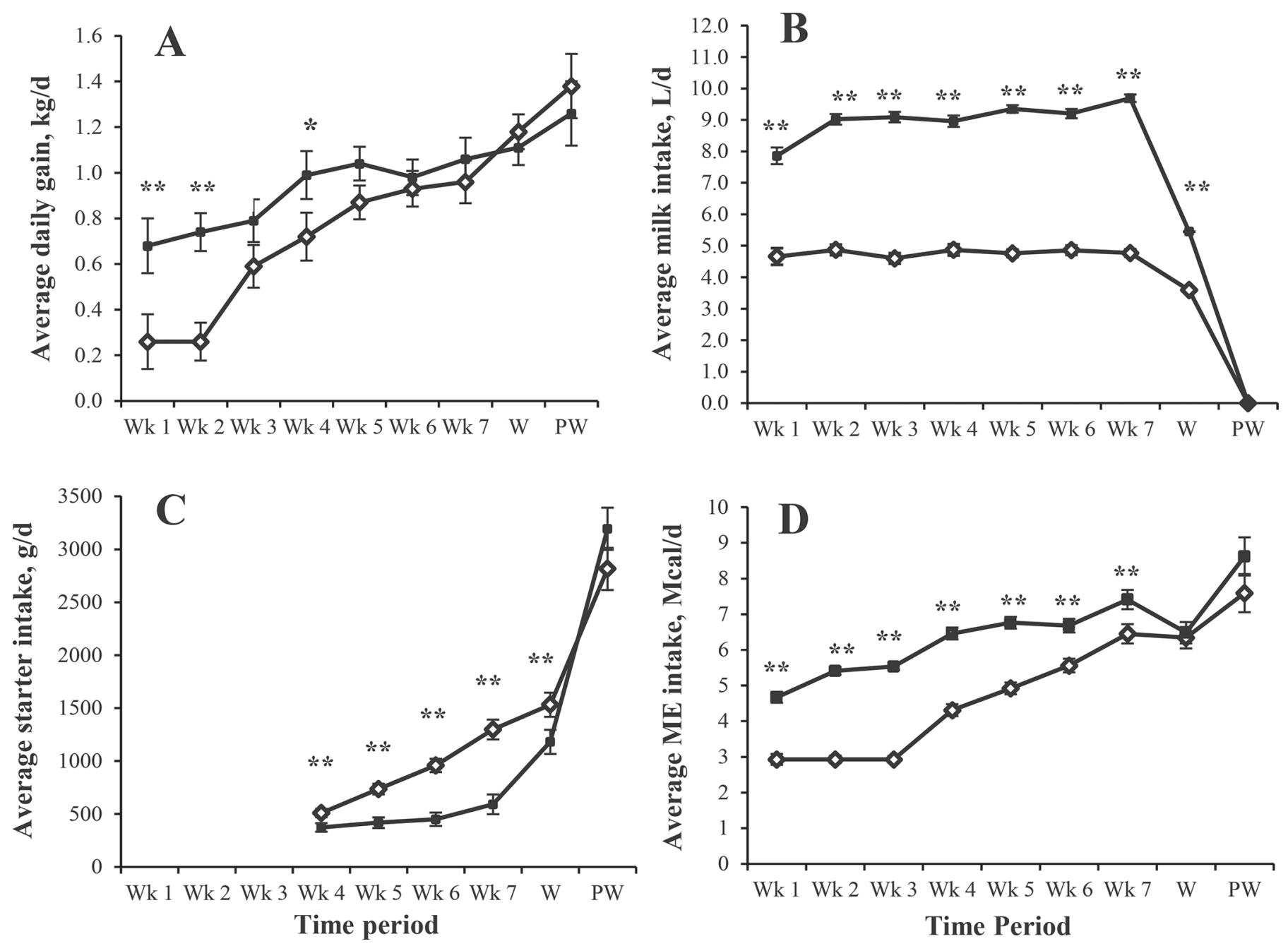

Figure 1. Average daily gain (A), milk intake (B), and average total ME intake (D) of calves fed a high (solid square; $10 \mathrm{~L} / \mathrm{d}, \mathrm{n}=13)$ or low (open diamond; $5 \mathrm{~L} / \mathrm{d}, \mathrm{n}=13$ ) level of milk preweaning (weekly average wk 1 to 7 ), through a 10-d weaning stepdown (time point W) and the week following weaning (time point PW). Starter intake $(\mathrm{C})$ was not measured for the first 3 wk of life. Significant differences are indicated at $P<0.05(* *)$ and tendencies at $P<0.10\left(^{*}\right)$. 
Total milk DMI was 47.6 vs. $25.9 \pm 1.3 \mathrm{~kg}(P<0.01)$ and total starter DMI was 48.7 vs. $56.6 \pm 5.1 \mathrm{~kg}(P$ $=0.29$ ) for $\mathrm{HI}$ and $\mathrm{LO}$, respectively; however, starter intake in the weeks before weaning and the 10-d weaning transition was lower for HI than LO (Figure 1C), but no difference was observed in the week postweaning between $\mathrm{HI}$ and $\mathrm{LO}$ calves $(P=0.19)$. Total ME intake was different throughout the preweaning period (Figure 1D); however, no difference was observed throughout the 10-d weaning transition or postweaning.

Body weight was not different between treatment groups at birth (42.0 vs $40.2 \pm 1.30 \mathrm{~kg}$ for $\mathrm{HI}$ and LO, respectively; $P=0.32$ ); however, differences in ADG were observed early in life (Figure 1A) with largest differences in ADG noted in the first 2 wk of life; however, few differences occurred thereafter. Overall, preweaning ADG was greater for $\mathrm{HI}$ than LO (0.90 vs. $0.65 \mathrm{~kg} / \mathrm{d} ; P$ $<0.01)$. Weekly ADG and ME intake was not different between the 2 treatments during the step-down and postweaning period. Total BW gain from birth until postweaning was 66.3 vs. $56.1 \pm 2.2 \mathrm{~kg}$ for HI versus LO $(P<0.01)$.

In the current study, feeding a high level of milk resulted in higher levels of IGF-1 detected at wk 1 until wk 5 and a tendency for an increased concentration of IGF-1 at wk 7. It has been previously shown that elevated feeding of nutrients from milk replacer preweaning increases IGF-1 (Bartlett et al., 2006; Daniels et al., 2008; Schaff et al., 2016); however, a noteworthy difference in our findings is a detectable difference in IGF-1 at wk 1 of life. Schaff et al. (2016) fed an elevated level of milk replacer for the first 5 wk of life, and despite differences in actual milk intake and $\mathrm{ME}$ intake among their calves fed a high versus a low plane of nutrition from wk 1, a difference in IGF-1 was not observed until $29 \mathrm{~d}$.

The major difference between the aforementioned study and the current one is that in our study HI calves consumed more ME from milk, and had a change in weight gain at wk 1 . Correlation analysis suggests that ADG was correlated with IGF-1 at wk $1(\mathrm{r}=0.18 ; P=$ $0.03)$ but not at wk $3(\mathrm{r}=0.03 ; P=0.42)$ or wk $5(\mathrm{r}=$ $0.07 ; P=0.18$ ). Milk intake during wk 1 was also correlated with IGF-1 concentrations $(\mathrm{r}=0.36 ; P<0.01)$, but not at wk $3(\mathrm{r}=0.07 ; P=0.22)$ or wk $5(\mathrm{r}=0.09$; $P=0.14)$. This suggests that nutrient intake during the first week of life is very important for synthesis of IGF1 and growth. It is also possible that feeding of whole milk influences levels of IGF-1. Extensive research with colostrum has led to mixed theories regarding whether IGF-1 present in colostrum is absorbed or feeding of it results in an increase in endogenous synthesis due to nutrient intake (Kirovski et al., 2002; Sparks et al.,
2003). As whole milk contains IGF-1 (Collier et al., 1991), and contains nutrients in a higher concentration than milk replacer, it is possible that both theories stand true for milk, and should be further investigated.

In comparison, ADG was correlated with IGF-1 at wk $7(\mathrm{r}=0.17 ; P=0.04)$ and wk $9(\mathrm{r}=0.30$; $P<0.01$ ), with IGF-1 being correlated to total ME intake at wk 7 and $9(\mathrm{r}=0.30 ; P<0.01$ and $\mathrm{r}=$ $0.29 ; P<0.01$, respectively). These findings support the importance of calves transitioning through weaning to maintain energy intake, IGF-1 concentrations, and growth. After weaning, no differences were observed between treatment with respect to IGF-1, energy intake, and growth, and therefore no carry-over effect of IGF-1 from preweaning to immediately postweaning was observed. There is a paucity of information about postweaning IGF-1 concentrations in plasma; therefore, a longer-term characterization of how IGF-1 concentrations in blood are altered during the postweaning period is warranted. Despite marked increases in IGF-1 when feeding HI, IGFBP-3 was found to be elevated in HI versus LO at wk 5 (Table $1 ; P<0.05$ ). Although IGFBP-3 was correlated with IGF-1 at each measured time point (data not presented), it is interesting as IGFBP-3 typically follows a similar change in plasma concentration as IGF-1 (Jones and Clemmons, 1995; Mohan and Baylink, 2002), as IGFBP-3 is the major carrier of IGF-1 and accounts for its stability in the blood.

The IGFBP-2 remained lower in HI calves throughout the milk feeding period (Table 1). It is possible that the difference between groups is due to the increased $\mathrm{ME}$ supply provided to HI calves preweaning, thus lowering IGFBP-2 concentrations, rather than the response being an increase in LO calves. It is known that IGFBP-2 typically exerts inhibitory effects on IGF-1 (Jones and Clemmons, 1995), which would suggest that low calves had reduced growth stimulation during the preweaning period via IGF-1. However, no correlations were found between ADG and IGFBP-2 preweaning for LO calves. This finding is supported by research in calves by Schaff et al. (2016), who found that IGFBP-2 was lower when calves were fed ad libitum levels of milk replacer up to 5 wk of age. Similarly, when Schaff et al. (2016) reduced the amount of milk fed to ad libitum calves to that of restricted calves, IGFBP-2 increased and then decreased until the end of the sampling period. Postweaning, at wk 9, IGFBP-2 concentrations found in HI calves increased such that there was no difference between treatments, suggesting that during the weaning transition $\mathrm{HI}$ calves did not receive sufficient levels of nutrients. In the current study, total ME intake was similar between treatments during this time 
(Figure 1D); however, HI calves had a reduction in ME intake during weaning, whereas LO calves increased ME intake.

Plasma concentrations of IGFBP-4 did not change when calves were fed a $\mathrm{HI}$ or LO level of milk, which is concurrent with other findings where IGFBP-4 did not change based on differing diets or plasma IGF-1 levels (Daniels et al., 2008). The whole milk fed in this study would have provided more energy and protein to LO calves, which may have reduced the levels of IGFBP-4 more than previously observed with milk replacer studies. Furthermore, no difference in IGFBP-5 was detected in this experiment even though it was expected to be decreased in HI calves, as it typically has been shown to have inhibitory effects on IGF-1 and is downregulated during a state of nutrient over-supply (Steele et al., 2011). The lack of difference in IGFBP-4 and IGFBP-5 between $\mathrm{HI}$ and $\mathrm{LO}$ calves indicates that not all IGFBP in plasma followed the classical responses previously reported in other species.

Overall, offering a high plane of nutrition as whole milk resulted in increased $\mathrm{BW}$ and changes in plasma concentrations of IGF-1 and IGFBP that correlate with the higher level of energy and protein supplied to calves preweaning. The results support previous findings in calves; however, there are minor differences in blood concentration of IGF-1 and IGFBP, especially IGFBP-3, which may be explained by feeding method or by the use of whole milk in the current experiment rather than milk replacer. A high plane of nutrition from milk during the first $7 \mathrm{wk}$ of life improved calf growth, increased IGF-1, and altered IGFBP, which are indicators of growth and development. Although these were inferred to be beneficial at the measured time points, whether these changes preweaning led to beneficial effects in the long term remains to be investigated.

Table 1. Weekly plasma concentrations of IGF-1, IGF binding protein (IGFBP)-2, IGFBP-3, IGFBP-4, IGFBP-5, and the ratio of IGFBP-3/IGFBP-2 pre- and postweaning when calves were offered a high $(10 \mathrm{~L} / \mathrm{d}$, $\mathrm{n}=13)$ or low $(5 \mathrm{~L} / \mathrm{d}, \mathrm{n}=13)$ level of milk preweaning

\begin{tabular}{|c|c|c|c|c|}
\hline \multirow[b]{2}{*}{ Variable } & \multicolumn{2}{|c|}{ Treatment } & \multirow[b]{2}{*}{ SEM } & \multirow[b]{2}{*}{$P$-value } \\
\hline & Low & High & & \\
\hline \multicolumn{5}{|c|}{ IGF-1, ng/mL } \\
\hline Wk 1 & 97 & 136 & 12.2 & 0.03 \\
\hline Wk 3 & 107 & 231 & 12.4 & 0.01 \\
\hline Wk 5 & 107 & 214 & 10.9 & 0.01 \\
\hline Wk 7 & 172 & 215 & 18.1 & 0.10 \\
\hline Wk 9 & 207 & 183 & 18.6 & 0.36 \\
\hline \multicolumn{5}{|c|}{ IGFBP-2, ng/mL } \\
\hline Wk 1 & 616 & 436 & 62.6 & 0.06 \\
\hline Wk 3 & 767 & 497 & 54.3 & 0.01 \\
\hline Wk 5 & 786 & 515 & 52.2 & 0.01 \\
\hline Wk 7 & 700 & 486 & 56.3 & 0.01 \\
\hline Wk 9 & 752 & 801 & 65.5 & 0.60 \\
\hline \multicolumn{5}{|c|}{ IGFBP-3, ng/mL } \\
\hline Wk 1 & 463 & 463 & 50.4 & 0.99 \\
\hline Wk 3 & 403 & 504 & 33.5 & 0.04 \\
\hline Wk 5 & 382 & 507 & 33.4 & 0.01 \\
\hline Wk 7 & 417 & 456 & 34.3 & 0.43 \\
\hline Wk 9 & 484 & 460 & 39.3 & 0.68 \\
\hline \multicolumn{5}{|c|}{ IGFBP-4, ng/mL } \\
\hline Wk 1 & 231 & 174 & 28.6 & 0.17 \\
\hline Wk 3 & 146 & 140 & 18.9 & 0.83 \\
\hline Wk 5 & 133 & 132 & 18.1 & 0.97 \\
\hline Wk 7 & 116 & 112 & 12.5 & 0.85 \\
\hline Wk 9 & 122 & 116 & 15.9 & 0.78 \\
\hline \multicolumn{5}{|c|}{ IGFBP-5, ng/mL } \\
\hline Wk 1 & 553 & 482 & 59.5 & 0.40 \\
\hline Wk 3 & 539 & 640 & 57.3 & 0.22 \\
\hline Wk 5 & 501 & 570 & 45.2 & 0.29 \\
\hline Wk 7 & 591 & 538 & 46.3 & 0.43 \\
\hline Wk 9 & 588 & 478 & 55.9 & 0.18 \\
\hline \multicolumn{5}{|c|}{ IGFBP-3/IGFBP-2 ratio } \\
\hline Wk 1 & 0.91 & 1.13 & 0.13 & 0.26 \\
\hline Wk 3 & 0.58 & 1.10 & 0.08 & 0.01 \\
\hline Wk 5 & 0.53 & 1.03 & 0.08 & 0.01 \\
\hline Wk 7 & 0.67 & 1.00 & 0.10 & 0.02 \\
\hline Wk 9 & 0.73 & 0.60 & 0.08 & 0.29 \\
\hline
\end{tabular}




\section{ACKNOWLEDGMENTS}

The authors acknowledge the support provided by Alberta Milk (Edmonton, AB, Canada), the Dairy Research and Technology Endowment Fund, Growing Forward 2 (Alberta Agriculture and Forestry, Edmonton, AB, Canada), a federal-provincial-territorial initiative, Natural Sciences and Engineering Research Council (Ottawa, ON, Canada), BC Dairy Association (Burnaby, BC, Canada), SaskMilk (Regina, SK, Canada), Dairy Farmers of Manitoba (Winnipeg, MB, Canada), Westgen (Abbotsford, BC, Canada), and Lallemand (Montreal, QC, Canada).

\section{REFERENCES}

AOAC International. 2002. Official Methods of Analysis. AOAC International, Arlington, VA.

Bartlett, K. S., F. K. McKeith, M. J. VandeHaar, G. E. Dahl, and J. K. Drackley. 2006. Growth and body composition of dairy calves fed milk replacers containing different amounts of protein at two feeding rates. J. Anim. Sci. 84:1454-1467.

Chamorro, M. F., P. H. Walz, D. M. Haines, T. Passler, T. Earleywine, R. A. Palomares, K. P. Riddell, P. Galik, Y. Zhang, and M. D. Givens. 2014. Comparison of levels and duration of detection of antibodies to bovine viral diarrhea virus 1 , bovine viral diarrhea virus 2 , bovine respiratory syncytial virus, bovine herpesvirus 1 ,and bovine parainfluenza virus 3 in calves fed maternal colostrum or a colostrum-replacement product. Can. J. Vet. Res. 78:81-88.

Chelack, B. J., P. S. Morley, and D. M. Haines. 1993. Evaluation of methods for dehydration of bovine colostrum for total replacement of normal colostrum in calves. Can. Vet. J. 34:407-412.

Collier, R. J., M. A. Miller, J. R. Hildebrandt, A. R. Torkelson, T. C. White, K. S. Madsen, J. L. Vicini, P. J. Eppard, and G. M. Lanza. 1991. Factors affecting insulin-like growth factor-I concentration in bovine milk. J. Dairy Sci. 74:2905-2911.

Daniels, K. M., S. R. Hill, K. F. Knowton, R. E. James, M. L. McGilliard, and R. M. Akers. 2008. Effects of milk replacer composition on selected blood metabolites and hormones in preweaned Holstein heifers. J. Dairy Sci. 91:2628-2640.

Hammon, H., and J. W. Blum. 1997. The somatotropic axis in neonatal calves can be modulated by nutrition, growth hormone and Long-R3-IGF-I. Am. J. Physiol. 273:E130-E138.
Hammon, H. M., J. Steinhoff-Wagner, U. Schönhusen, C. C. Metges, and J. W. Blum. 2012. Energy metabolism in the newborn farm animal with emphasis on the calf: Endocrine changes and responses to milk-born and systemic hormones. Domest. Anim. Endocrinol. 43:171-185.

Hammon, H. M., I. A. Zanker, and J. W. Blum. 2000. Delayed colostrum feeding affects IGF-I and insulin plasma concentrations in neonatal calves. J. Dairy Sci. 83:85-92.

Jones, J. I., and D. R. Clemmons. 1995. Insulin-like growth factors and their binding proteins: Biological actions. Endocr. Rev. 16:3-34.

Kirovski, D., V. Stojić, and J. A. Nikolić. 2002. Serum levels of insulinlike growth factor-I and total protein in newborn calves offered different amounts of colostrum. Acta Veterinaria 2:285-298.

Mohan, S., and D. J. Baylink. 2002. IGF-binding proteins are multifunctional and act via IGF-dependent and -independent mechanisms. J. Endocrinol. 175:19-31.

NRC. 2001. Nutrient Requirements of Dairy Cattle. 7th ed. National Academy Press, Washington, DC.

Renaville, R., M. Hammadi, and D. Portelle. 2002. Role of the somatotropic axis in the mammalian metabolism. Domest. Anim. Endocrinol. 23:351-360.

Rosenberger, K., J. H. C. Costa, H. W. Neave, M. A. G. von Keyserlingk, and D. M. Weary. 2017. The effect of milk allowance on behavior and weight gains in dairy calves. J. Dairy Sci. 100:504-512.

Schaff, C., J. Gruse, J. Maciej, M. Mielenz, E. Wirhgen, A. Hoeflich, M. Schmiche, R. Pfuhl, P. Jawor, T. Stefaniak, and H. H. Hammon. 2016. Effects of feeding milk replacer ad libitum or in restricted amounts for the first five weeks of life on the growth, metabolic adaptation, and immune status of calves. PLoS One 11:e0168974. https://doi.org/10.1371/journal.pone.0168974.

Sparks, A. L., J. G. Kirkpatrick, C. S. Chamberlain, D. Waldner, and L. J. Spicer. 2003. Insulin-like growth factor-1 and its binding proteins in colostrum compared to measures in serum of Holstein neonates. J. Dairy Sci. 86:2022-2029.

Steele, M. A., J. Croom, M. Kahler, O. AlZahal, S. E. Hook, K. C. Plaizier, and B. W. McBride. 2011. Bovine rumen epithelium undergoes rapid structural adaptations during grain-induced subacute ruminal acidosis. Am. J. Physiol. Regul. Integr. Comp. Physiol. 300:R1515-R1523.

Yu, H., J. Mistry, M. J. Nicar, M. J. Khosravi, A. Diamindis, J. voon Doorn, and A. Juul. 1999. Insulin-like growth factors (IGF-I, Free IGF-I and IGFII) and insulin like growth factor binding proteins (IGFBP-2, IGFBP-3, IGFBP-6, and ALS) in blood circulation. J. Clin. Lab. Anal. 13:166-172. 